\title{
Microstructural Evaluation of Durability of Different Cementitious Mixtures in Microbial Induced Corrosion Environments
}

\author{
Chunyu Qiao ${ }^{1}$ and David Rothstein ${ }^{2}$ \\ ${ }^{1}$ DRP, A Twining Company, 80301-Boulder, USA, joe@drpcinc.com \\ ${ }^{2}$ DRP, A Twining Company, 80301-Boulder, USA, petro@drpcinc.com
}

\begin{abstract}
Sound and durable concrete mixtures are essential in environments where microbial induced corrosion (MIC) is a concern. In this study three concrete mixtures prepared with different binders (ordinary portland cement (OPC), calcium aluminate cement (CAC) and alkali-activated cement (AAC) were petrographically examined after exposure to laboratory-controlled MIC conditions. Analytical techniques included reflected light microscopy, polarized and fluorescent transmitted light microscopy (FLM) and scanning electron microscopy equipped with an energy-dispersive X-ray spectrometer (SEM/EDX). SEM/EDX analyses obtained from the same areas provided information on chemical and mineralogical alteration, while quantitative image analysis with FLM affords an opportunity to quantify the variation in capillary porosity of the paste within alteration zonation. The microscopic observations indicate that the change in normalized capillary porosity coincide broadly with different alteration zones, which are in turn dependent on the type of binder. The OPC concrete shows the greatest deterioration where the paste is largely replaced by gypsum and high capillary porosity is lined to leaching of a calcium. The formation of ettringite densifies the paste and lowers the capillary porosity inboard of the gypsum zone in the OPC concrete. The CAC and AAC mixtures show better resistance to leaching than the OPC mixture, which explains their superior resistance to MIC. These findings are consistent with independent macroscopic observations that indicate the OPC mixture deteriorated more rapidly and severely than the $C A C$ and $A A C$ mixtures.
\end{abstract}

Keywords: Microstructure, Fluorescence Microscopy, Microbial Induced Corrosion, Cementitious Materials, Image Analysis.

\section{Introduction}

Microbial Induced Corrosion (MIC) is a significant concern for the condition of concrete infrastructure elements in a variety of environments (Grengg et al., 2015). There is a longstanding recognition that one of the most significant of these environments include wastewater treatment plants (WWTP) and sewer lines, where biological activity from bacteria such as Acidithiobacillus thiooxidans lead to rapid rates of deterioration as hydrogen sulfide gas forms sulfuric acid on concrete surfaces above flow lines in sewers and in digesting basins within WWTP (Parker, 1945). In the United States, much of the concrete WWTP infrastructure was built in the 1970s and is approaching its design life of $\sim 50$ years. Prolonging the use of these facilities and the sustainability of the built infrastructure requires the use of sound and durable repair materials. Because these repairs are often the responsibility of local municipalities with limited financial resources, repair and remediation strategies and materials must also be economically viable.

This study assesses the resistance of three of the most commonly used and widely available (and therefore economic) materials for WWTP facilities: ordinary portland cement (OPC), 
calcium aluminate cement (CAC), and alkali activated fly ash and slag (AAC). Optical and electron microscopical methods are used to characterize the response of these materials to MIC simulated in a biogenic corrosion chamber. In particular, we use fluorescence light microscopy to measure the evolution of the capillary porosity of the different binders as they undergo MIC.

\section{Mixtures and Experimental Procedures}

\subsection{Mixtures}

This study investigates three concrete mixtures made with different binders: ordinary portland cement (OPC), calcium aluminate cement (CAC), and alkali activated fly ash and slag (AAC). Table 1 summarizes the mixture proportions used to produce specimens that were cast in molds measuring $400 \mathrm{~mm}$ by $100 \mathrm{~mm}$ by $100 \mathrm{~mm}$. The specimens were demolded after $24 \mathrm{hrs}$ and then cured in a moist room for OPC concrete, in water for CAC concrete and in a regular room for AAC concrete. All of the specimens were cured for 28 days at $22 \pm 1{ }^{\circ} \mathrm{C}$. Coupons that measure $100 \mathrm{~mm}$ by $70 \mathrm{~mm}$ by $70 \mathrm{~mm}$ were cut for the biogenic acid exposure testing.

Table 1. Mixture Proprotions of three concretes $\left(\mathrm{kg} / \mathrm{m}^{3}\right)$.

\begin{tabular}{cccc}
\hline & OPC concrete & CAC concrete & AAC concrete \\
\hline Binder & 450 & 450 & 450 \\
\hline Coarse aggregate & 1025 & 1035 & 1045 \\
\hline Fine aggregate & 730 & 768 & 790 \\
\hline Water & 160 & 189 & 195 \\
\hline w/b & 0.36 & 0.42 & 0.43 \\
\hline
\end{tabular}

The exposed surface of each coupon was pre-treated to facilitate the growth of the acidophilic

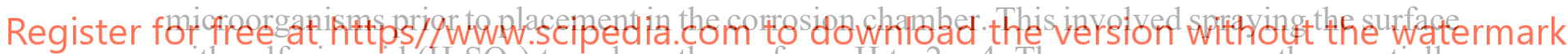
with sulfuric acid $\left(\mathrm{H}_{2} \mathrm{SO}_{4}\right)$ to reduce the surface $\mathrm{pH}$ to $2-4$. The coupons were then partially submerged in real sewage water in an enclosed chamber at $25^{\circ} \mathrm{C}$ and $100 \%$ relative humidity

(RH). The exposure test lasted for 12 months. The coupons were then removed from the chamber and washed to remove loose material. Measurements of the mass of the coupons before, during and after the exposure testing indicated the most significant mass loss and deterioration on a macroscopic scale in the OPC, followed by the CAC and then the AAC.

A slab representing a cross section of each coupon was cut, lapped and polished with progressively finer diamond-embedded pads following procedures outlined in ASTM C457. The polished slabs were oven dried overnight at $\sim 40^{\circ} \mathrm{C}$ and examined using Nikon ${ }^{\circledR} \mathrm{SMZ}-25$ stereomicroscope following ASTM C856.

A billet measuring $40 \mathrm{~mm}$ by $25 \mathrm{~mm}$ in area was cut from the remaining portion of each coupon. The billets were rinsed in an aqueous solution, oven dried overnight at $\sim 40^{\circ} \mathrm{C}$ and then vacuum impregnated with an epoxy containing a fluorescent dye. Thin sections were prepared from the impregnated billets using a Pelcon ${ }^{\circledR}$ Automatic Thin Section Machine. The thin sections were examined using a Nikon ${ }^{\circledR}$ E-Pol 600 petrographic microscope. Images were obtained in fluorescence mode and image analysis software (Image J) was used to create grayscale images and make measurements of the capillary of the paste. 
Another billet impregnated with fluorescent epoxy was cut and polished for examination using a FEI ${ }^{\mathrm{TM}}$ Quanta 250 Environmental Scanning Electron Microscope (ESEM) coupled with an $\mathrm{EDAX}^{\circledR}$ Apollo X Silicon Drift energy dispersive X-ray spectrometer (EDX). The specimens were examined under low vacuum conditions $(\sim 70 \mathrm{~Pa})$ with an accelerating voltage of $15 \mathrm{kV}$, a spot size of 5 and a working distance of $\sim 10 \mathrm{~mm}$.

\section{Results and Discussions}

\subsection{OPC Concrete}

Leemann et al. (2006) used fluorescence microscopy to investigate variations in porosity across the interfacial transition zone (ITZ) in self consolidated concrete. A similar analysis is performed in this paper to measure changes in capillary porosity across alteration zones. As a benchmark, the grey level histograms of paste (in Fig. 1a) and a void (in Fig.1b) were analyzed and statistically fitted assuming normal distributions, as shown in Fig. 1c. Since the void in Fig. $1 \mathrm{~b}$ is filled with epoxy containing a fluorescent dye and has $100 \%$ porosity, a "normalized capillary porosity" of the paste is proposed by normalize the mean grey level of the paste to that of the air void. The standard deviation is used as the error bar, as shown in Fig. 2g.

Optical and scanning electron microscopical examination of the sample revealed several distinct mineralogical and chemical alteration zones (Fig. 2a-2e). The alteration zones are as follows, moving inward from the exposed surface: (a) coarse-grained gypsum; (b) medium-

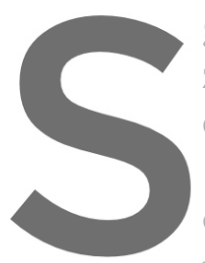
grained gypsum; (c) a transition zone with et
zone; and (e) a zone of calcium leaching. F
changes in the capillary porosity of the paste it
The alteration of the OPC concrete is typ
observed in OPC concretes exposed to MIC. reactions typical of these environments. The
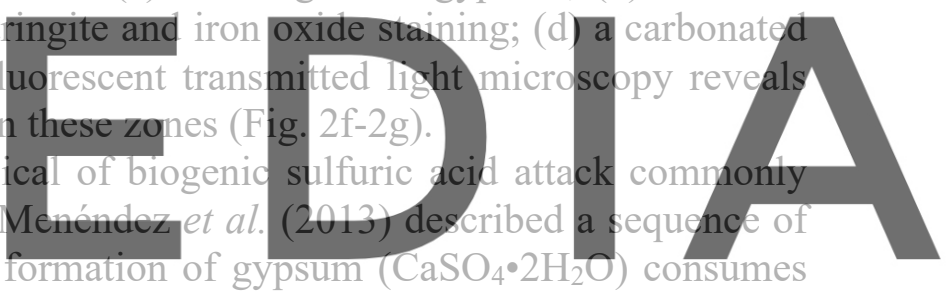
calcium hydroxide $\left(\mathrm{Ca}(\mathrm{OH})_{2}\right.$ ) and calcium silicate hydrates $(\mathrm{CSH})$ in the paste matrix. The

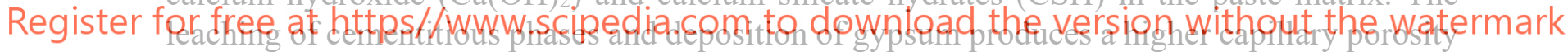
in Zone (a) and Zone (b). In particular, because Zone (a) is in contact with an acidic solution, there is widespread dissolution of $\mathrm{CSH}$ and a dramatic increase in capiliary porosity (Fig. $2 \mathrm{~g}$ ). Ettringite forms in Zone (c) because the $\mathrm{pH}$ sufficiently high to stabilize it this far inboard of the exposed surface. The iron staining in Zone (c) is due to the oxidization of iron-bearing accessory minerals in the aggregate that is mainly basalt and andesite. These reactions are expansive, which lowers the capillary porosity inboard of the outer alteration zones, compared to that of the intact paste (Fig. $2 \mathrm{~g}$ ). The carbonated zone, which is relatively thin, also shows decreased capillary porosity. Inboard of the carbonated zone, the leaching of $\mathrm{Ca}^{2+}$ in Zone (e) results in a slight increase in capillary porosity, compared to the intact paste (Fig. 2g). 

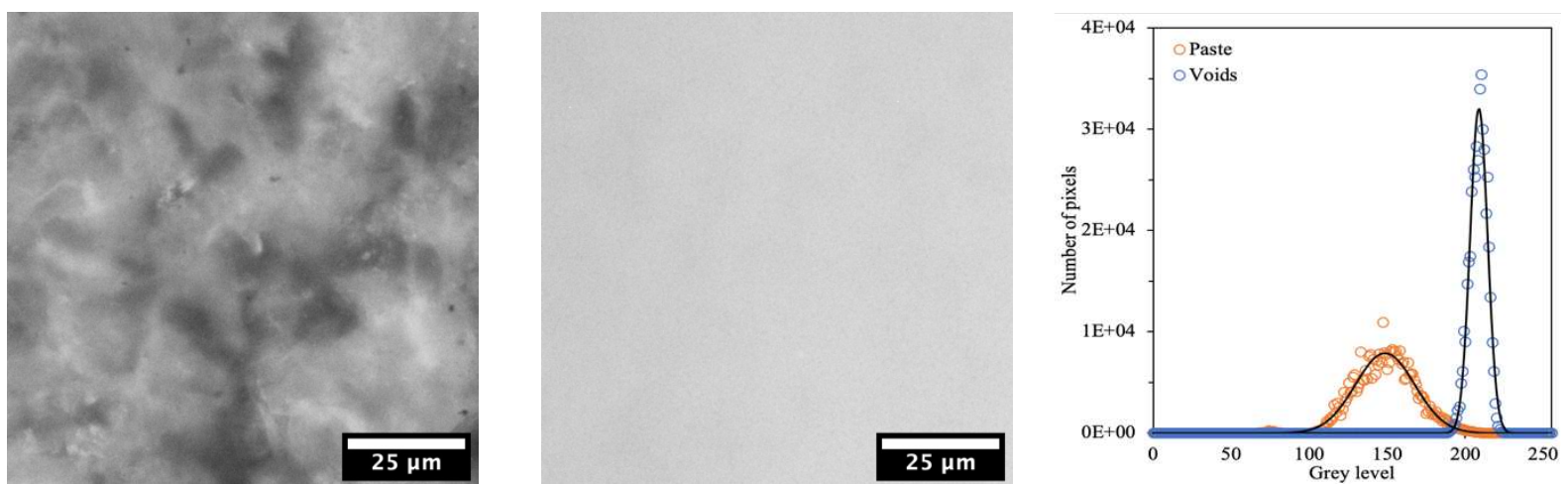

Figure 1. Determination of normalized capillary porosity in OPC: (a) paste; (b) voids; (c) grey level histograms
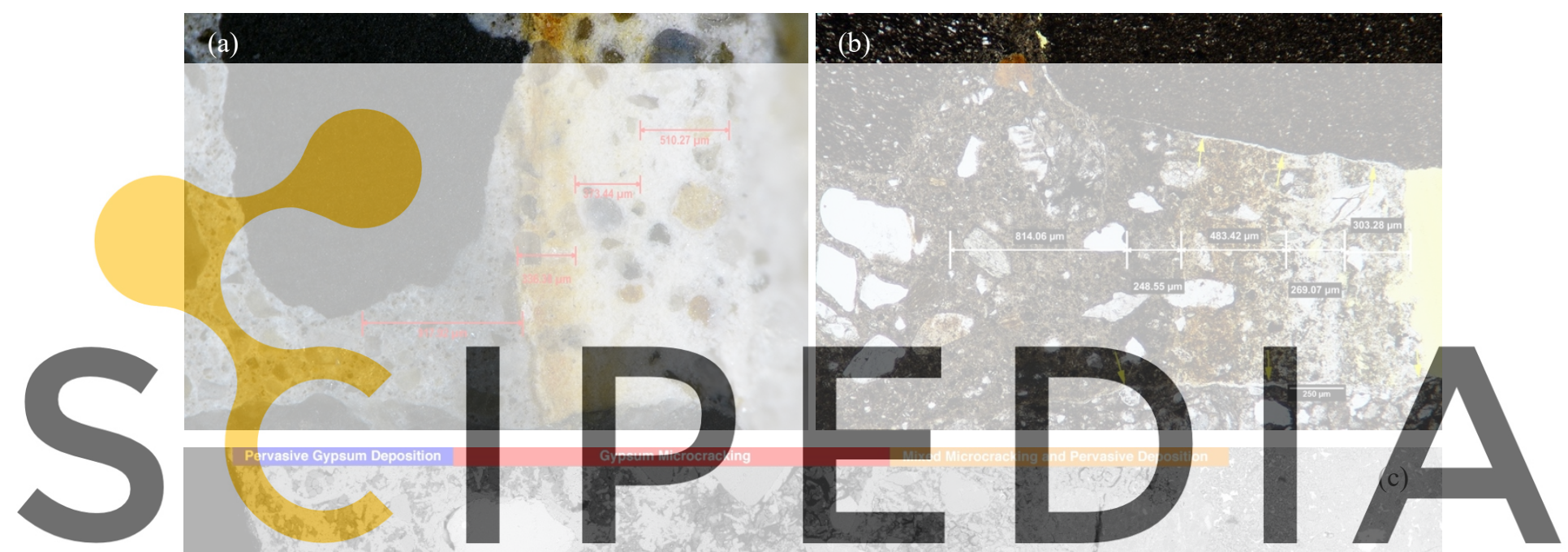

Register for free at https//www.scipedia.com to download the version without the watermark
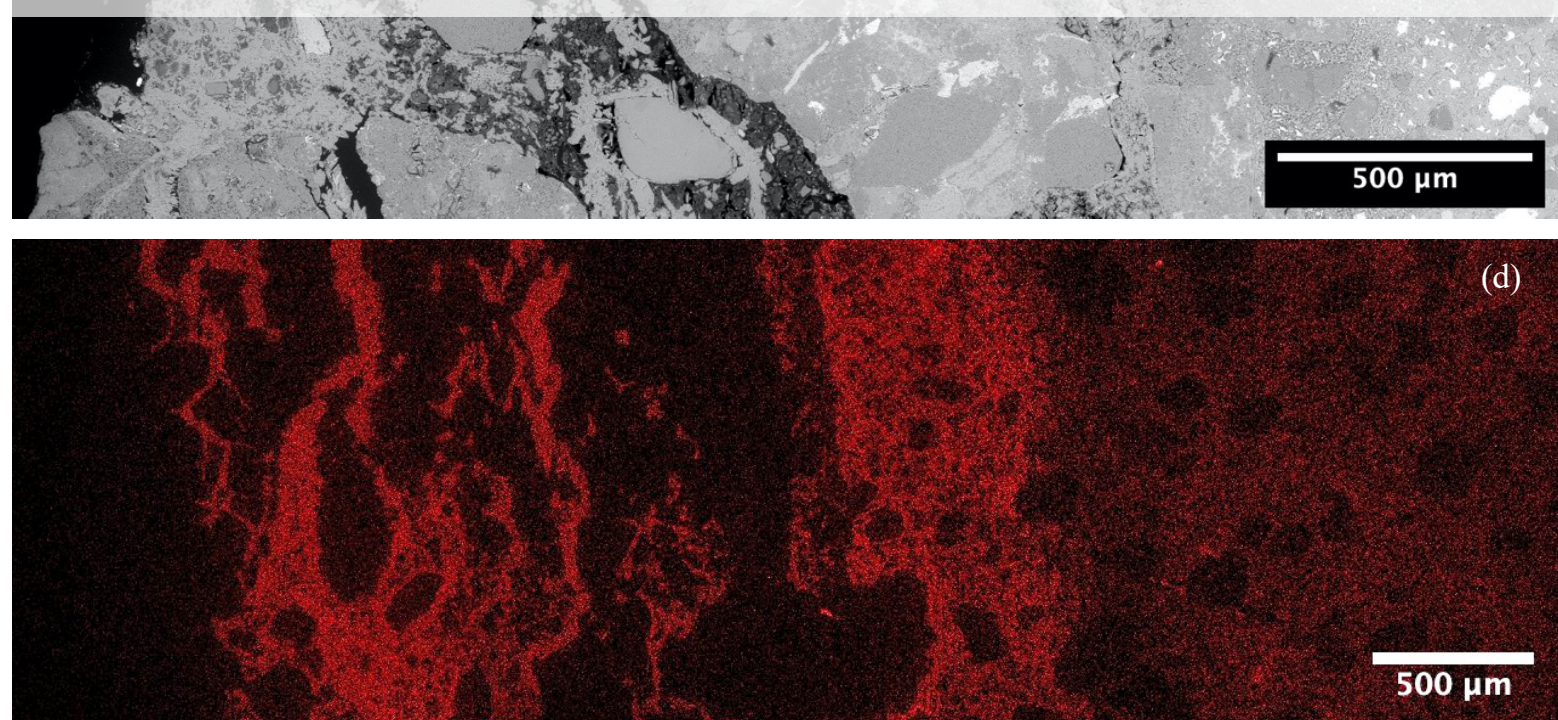

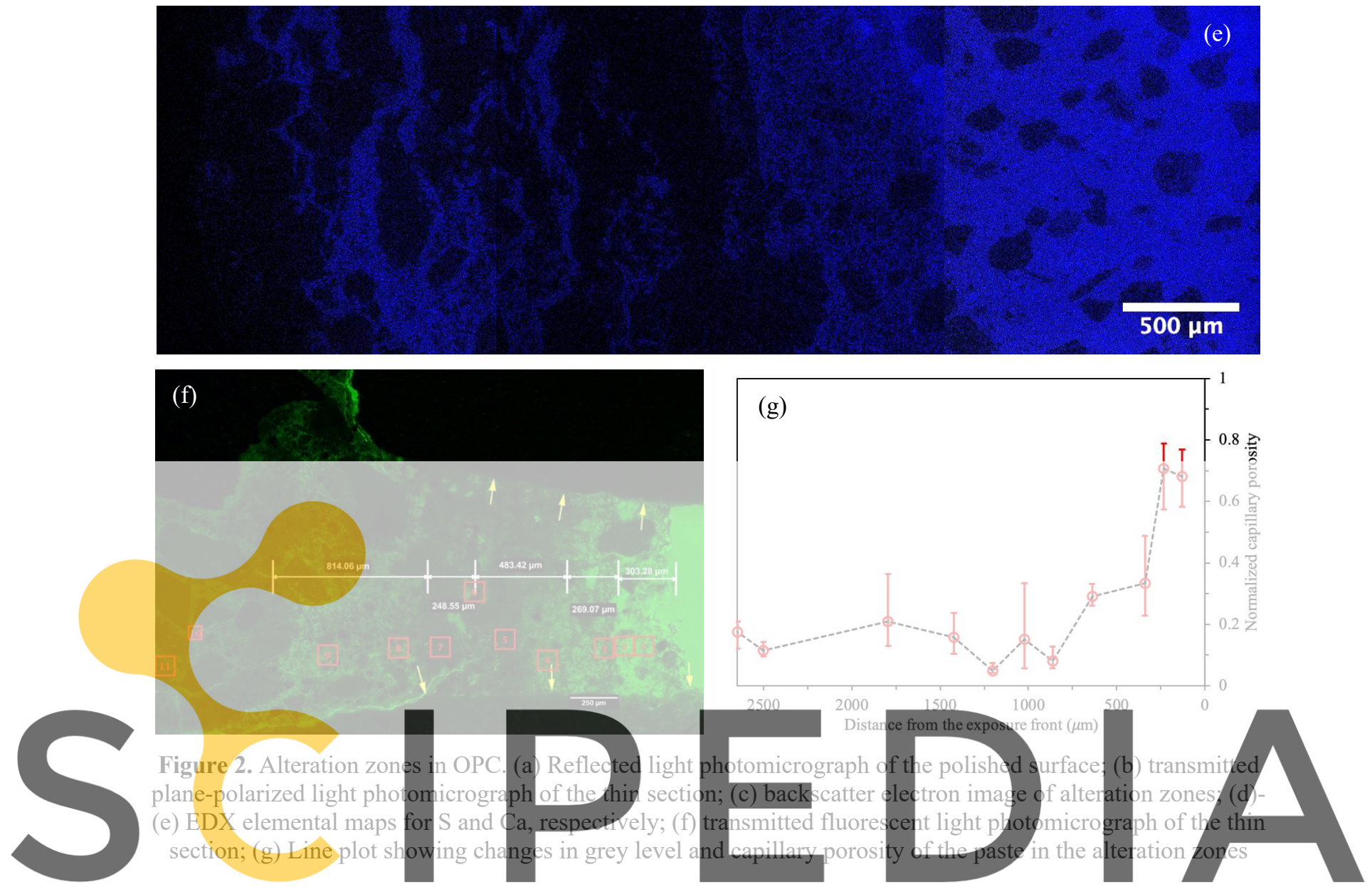

\subsection{CAC Concrete}

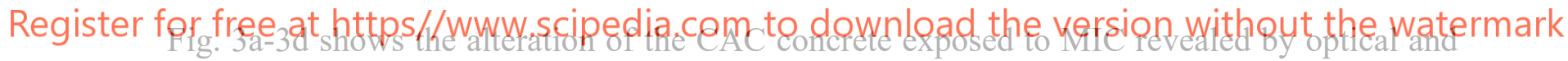

electron microscopy. The alteration zones are as follows (inwards from the exposure surface):

(a) a zone of pervasive cracking with deposition of gypsum (in Fig. 3a), which was lost on the thin section during the sample preparation (in Fig.3b); (b) a transition zone that contains gypsum, ettringite and iron oxide staining; and (c) sulfate diffusion zone. As shown in Fig. 3f, the capillary porosity of the paste decreases from the intact paste to Zone (b). This indicates the sulfate attack lowers the capillary porosity to some extent before there is sufficient internal expansion to crack the concrete.

The main hydration products of the CAC concrete depend on the curing conditions ( $\mathrm{RH}$ and $\mathrm{T}$ ), w/b ratio and curing time (Schmitt et al., 2000). The main hydration products of CAC concrete (cured in water at $22 \pm 1{ }^{\circ} \mathrm{C}$ ) include hydrogarnet $\left(3 \mathrm{CaO} \cdot \mathrm{Al}_{2} \mathrm{O}_{3} \cdot 6 \mathrm{H}_{2} \mathrm{O}, \mathrm{C}_{3} \mathrm{AH}_{6}\right)$ and gibbsite $\left(\mathrm{Al}(\mathrm{OH})_{3}, \mathrm{AH}_{3}\right)$. Khan et al. (2019) described the alteration of $\mathrm{CAC}$ in such environments. The most significant reactions involve the formation of gypsum and gibbsite from hydrogarnet in the presence of sulfuric acid. These reactions are expansive and lead to cracking in Zone (a). In the transition Zone (b), gypsum reacts with hydrogarnet to form ettringite (Khan et al., 2019), which densifies the microstructure of the paste before the internal stress cracks the concrete. This explains the lower capillary porosity in Zone (b) and Zone (c), 
compared to the intact paste (Khan et al., 2019; Nishikawa et al., 1992).
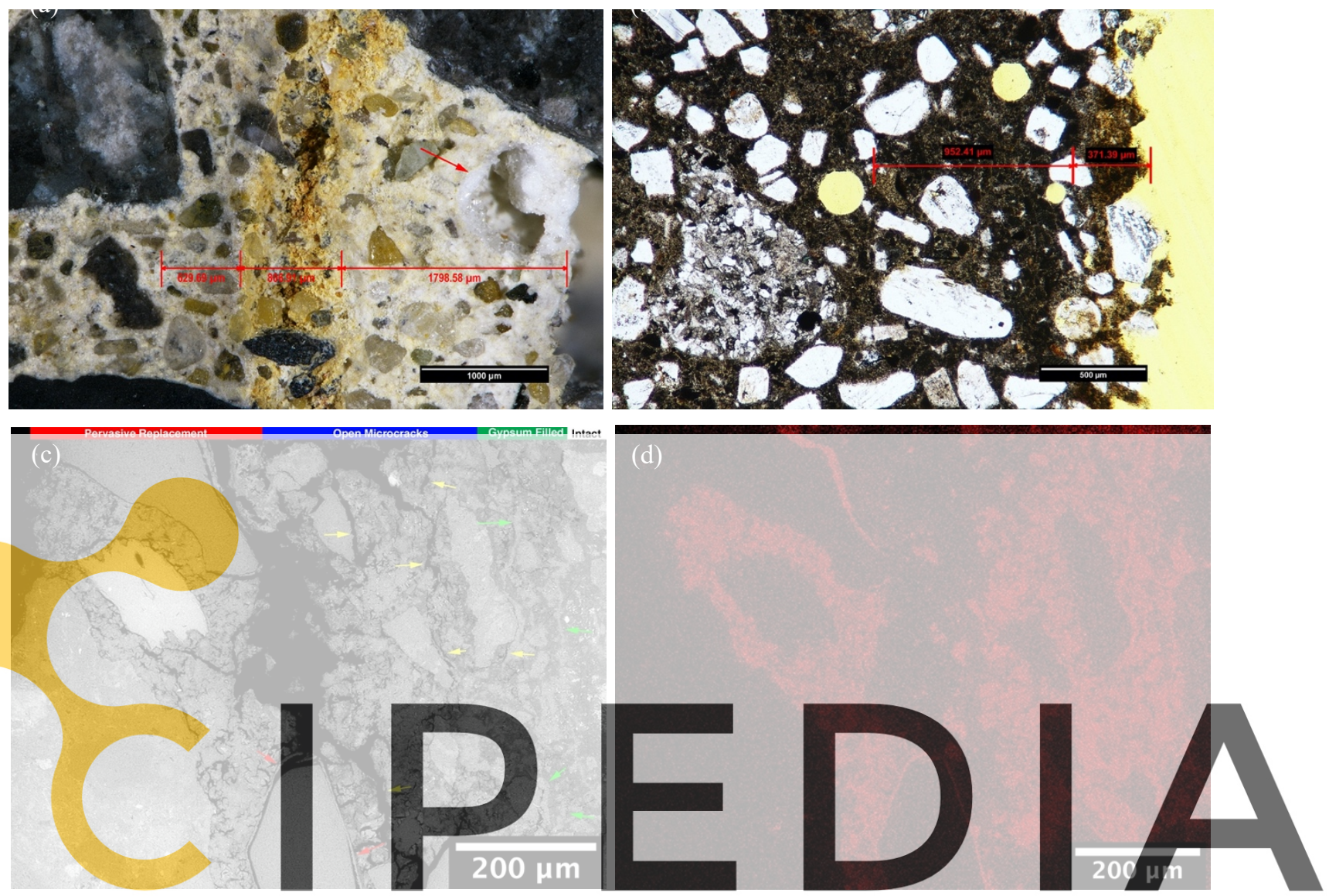

Register for free at https//www.scipedia.com to
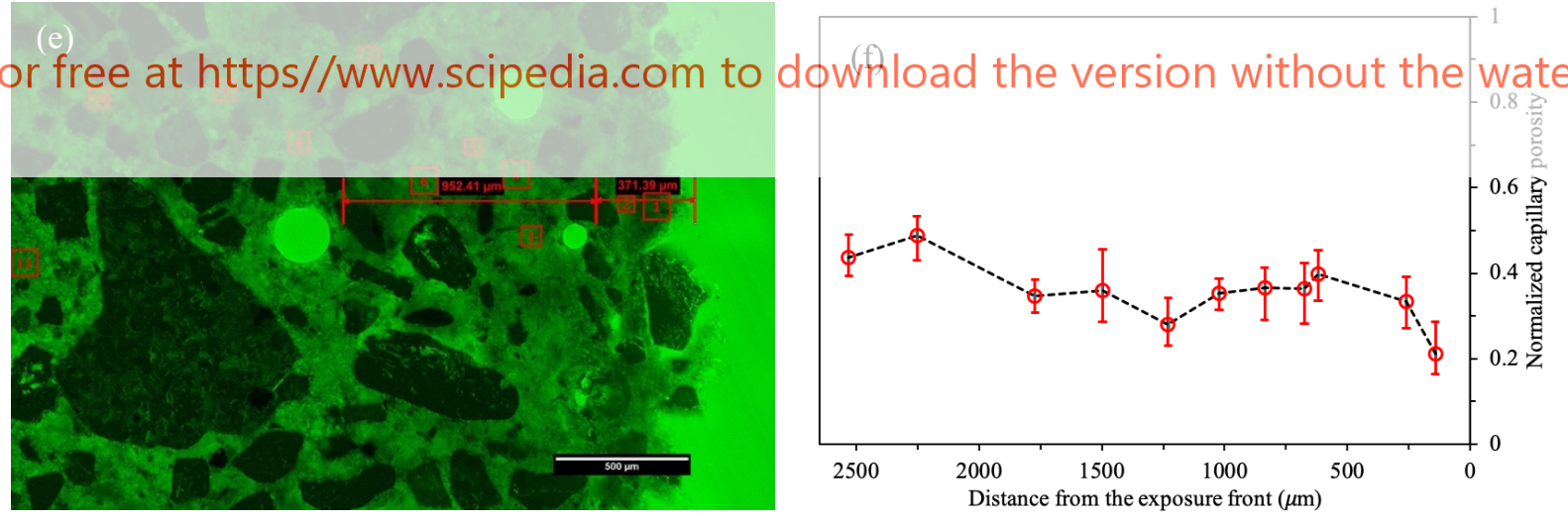

Figure 3. Alteration zones in the CAC concrete. (a) Reflected light photomicrograph of the polished surface; (b) transmitted plane-polarized light photomicrograph of the thin section; (c) backscatter electron image of alteration zones; (d) EDX elemental map for S; (e) transmitted fluorescent light photomicrograph of thin section; (f) Line plot showing changes in grey level and capillary porosity of the paste in the alteration zones.

\subsection{AAC Concrete}

Fig. 4a-4d shows the alteration zones observed in the AAC concrete exposed to sulfate attack. Similar to the alteration observed in CAC concrete, the alteration in AAC concrete involves the 
following: (a) a zone of pervasive gypsum deposition and cracking; (b) a transition zone that contains a mixture of gypsum, ettringite and iron oxide staining; and (c) a sulfate diffusion zone. Calcium (alkali) aluminosilicate hydrate $(\mathrm{C}-(\mathrm{N})-\mathrm{A}-\mathrm{S}-\mathrm{H})$ and monosulfate $(\mathrm{AFm})$ are two of the main hydration products in AAC concrete (Myers et al., 2017). These react with $\mathrm{H}_{2} \mathrm{SO}_{4}$ to form gypsum, which results in pervasive gypsum deposition, leaching of the paste and cracking in Zone (a). Higher capillary porosity was observed in Zone (a) compared to that of the intact paste (Fig. 4e-4f). In the transition Zone (b) and diffusion Zone (c), the formation of ettringite from AFm densifies the microstructure and a lower capillary porosity, compared to that of the intact paste, is observed.

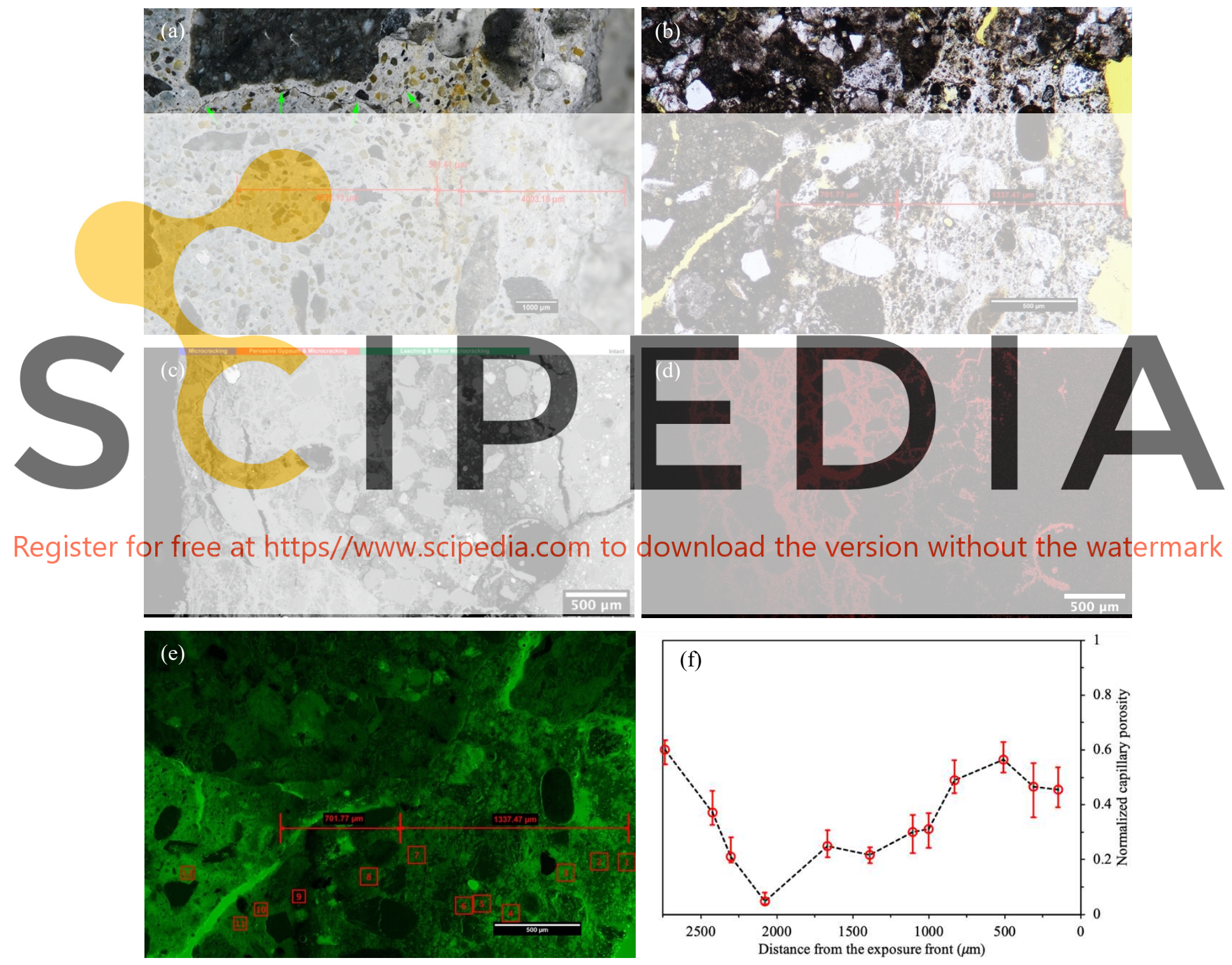

Figure 4. Observations of alteration zones in the AAC. (a) Reflected light photomicrograph of the polished surface; (b) transmitted plain-polarized light photomicrograph of the thin section; (c) Backscatter electron image of alteration zones; (d) EDX elemental map for S; (e) transmitted fluorescent light photomicrograph of the thin section; (f) Line plot showing changes in grey level and capillary porosity of the paste in the alteration zones. 


\section{Conclusions}

Petrographic examination of three concrete mixtures prepared with different binders and subjected to MIC under controlled laboratory conditions provides insight toward the durability of these materials in WWTP environments. Observations obtained from optical and electron microscopy clearly delineate alteration zones characterized not only by distinct mineralogy, but also by distinct changes in the capillary porosity or density of the paste. The OPC mixture shows the great deterioration where the outer alteration zones show both increased capillary porosity of the paste associated with the leaching of $\mathrm{Ca}(\mathrm{OH})_{2}$ and $\mathrm{CSH}$ and zones of significant cracking associated with the pervasive deposition of gypsum. Inboard of these zones the formation of ettringite actually densifies the OPC paste. The CAC and AAC mixtures show greater resistance to the sulfuric acid conditions associated with MIC than the OPC mixture. The outermost alteration zones in these mixtures have markedly lower capillary porosity than the OPC mixture. As such, the alteration zones are more cohesive and remain adhered to the intact paste, which explains why these samples show lower mass loss in macroscopic testing. The higher resistance is consistent with better resistance to leaching than the OPC mixtures, which is in turn due to the lack of $\mathrm{Ca}(\mathrm{OH})_{2}$ and $\mathrm{CSH}$ in these materials.

Acknowledgements

The authors thank Mr. Gaines Green for the preparation of samples for optical and scanning electron microscopy, Mr. James Aldred for comments on a report describing some aspects of the work presented here and Mr. Stephen

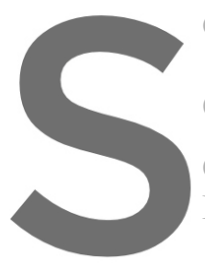
Grace for providing backgrol

S

Chunyu Qiao: http://orcid.

David Rothstein: http://or

References
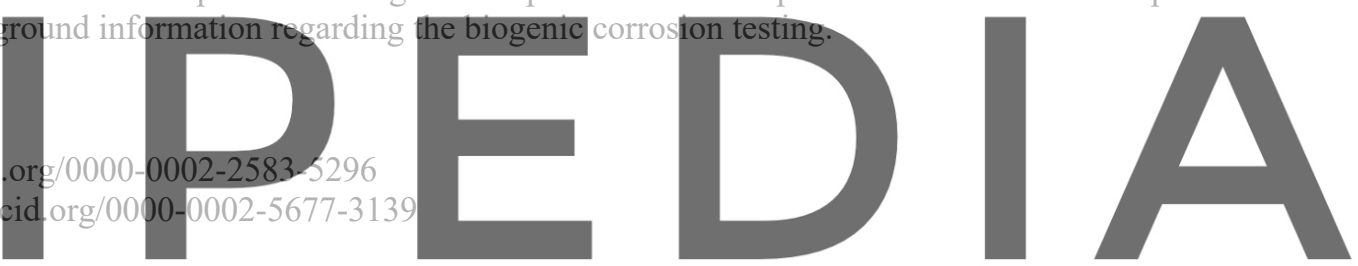

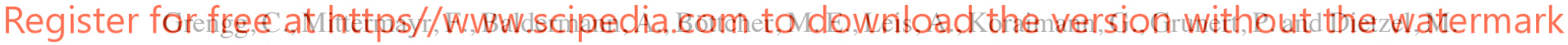
(2015). Microbiologically induced concrete corrosion: A case study from a combined sewer network. Cement and Concrete Research, 77, 16-25. doi:10.1016/j.cemconres.2015.06.011

Khan, H. A., Castel, A., Khan, M. S. H. and Mahmood, A. H. (2019). Durability of calcium aluminate and sulphate resistant Portland cement based mortars in aggressive sewer environment and sulphuric acid. Cement and Concrete Research, 124, 105852. doi:10.1016/j.cemconres.2019.105852

Leemann, A., Münch, B., Gasser, P. and Holzer, L. (2006). Influence of compaction on the interfacial transition zone and the permeability of concrete. Cement and Concrete Research, 36(8), 1425-1433. doi:10.1016/j.cemconres.2006.02.010

Menéndez, E., Matschei, T. and Glasser, F. P. (2013). Sulfate Attack of Concrete. In M. Alexander, A. Bertron, \& N. De Belie (Eds.), Performance of Cement-Based Materials in Aggressive Aqueous Environments: State-ofthe-Art Report, RILEM TC 211 - PAE (pp. 7-74). Dordrecht: Springer Netherlands.

Myers, R. J., Bernal, S. A. and Provis, J. L. (2017). Phase diagrams for alkali-activated slag binders. Cement and Concrete Research, 95, 30-38. doi:10.1016/j.cemconres.2017.02.006

Nishikawa, T., Suzuki, K., Ito, S., Sato, K. and Takebe, T. (1992). Decomposition of synthesized ettringite by carbonation. Cement and Concrete Research, 22(1), 6-14. doi:https://doi.org/10.1016/0008-8846(92)90130-N

Parker, C. D. (1945). THE CORROSION OF CONCRETE. Australian Journal of Experimental Biology and Medical Science, 23(2), 81-90. doi:10.1038/icb.1945.13

Schmitt, N., Hernandez, J.-F., Lamour, V., Berthaud, Y., Meunier, P. and Poirier, J. (2000). Coupling between kinetics of dehydration, physical and mechanical behaviour for high alumina castable. Cement and Concrete Research, 30(10), 1597-1607. doi:10.1016/S0008-8846(00)00342-2 